\title{
CLASSIFICAÇÃO DA TIPOLOGIA DA ORLA DA CIDADE DE OLINDA-PE: DELIMITAÇÃO E CARACTERIZAÇÃO
}

\author{
Tereza C. M.Araújo \\ Professora do Departamento de Oceanografia - UFPE \\ Av. Arquitetura, s/n, Cidade Universitária, 50739-540Recife - PE, Phone: 55 81-21267225 \\ e-mail: tcma@ufpe.br \\ Valéria B. Silva \\ Geógrafa, Aluna do XIV Curso de Especialização em Oceanografia, \\ Departamento de Oceanografia - UFPE, Av. Arquitetura, s/n, Cidade Universitária, 50739-540 Recife - PE \\ João A.R. Carvalho \\ Geógrafo, Aluno do XIV Curso de Especialização em Oceanografia \\ Departamento de Oceanografia - UFPE, Av. Arquitetura, s/n, Cidade Universitária, 50739-540 Recife - PE
}

\begin{abstract}
Resumo
A orla costeira é classificada como a área em contato direto entre continente e o mar. Devido ao seu alto grau de beleza cênica, é uma área de grande conflito, gerado pelos múltiplos usos deste mínimo espaço. Este trabalho tem como objetivo classificar os diferentes tipos da orla da cidade de Olinda-PE. Para isso, foram feitas observações visuais dos parâmetros paisagísticos da orla, coleta de sedimentos para análise granulométrica e tomadas fotografias em vários pontos para diagnóstico local. A tipologia da orla foi classificada em quatro categorias: orla exposta não urbanizada (20\%), orla exposta com urbanização consolidada (20\%), orla semi-abrigada com urbanização consolidada (14\%), e orla abrigada com urbanização consolidada $(46 \%)$. Na porção sul predomina a orla exposta enquanto na parte norte predomina a orla abrigada. $80 \%$ da orla apresenta urbanização consolidada. As várias intervenções antrópicas mudaram as características da cobertura sedimentar das praias. Em quase toda a área foi constatada a presença de obras de proteção costeira, devido ao agravamento do problema de erosão costeira que esta região enfrenta ao longo do tempo.
\end{abstract}

Palavras-Chave: tipologia da orla, gestão costeira, Olinda.

\begin{abstract}
The coastline is classified as a strait band in contact of land with the sea. Due to its higher beatiful setting it is an area with various conflicts, generated because its multiples uses. The aim os this work is to classify the differents kinds of coastline in the Olinda city. For them were conducted visual observations of the seascape parameters along the Olinda coastline, taken sediment samples and make photographies in several points. The thypology of the coastiline were classified in four categories: opened coastline without urbanization ( $20 \%$ ), opened coastline with consolidated urbanization ( $20 \%$ ), semi-protected coastline with consolidated urbanization (14\%) and protected coastline with consolidated urbanization (46\%). In the south portion predominates the opened coastline, and the protect coastline were found in the north portion. In the $80 \%$ of the total area predominates the coastline with consolidated urbanization. The multiples antropic interferences changed the sedimentological characteristics of the beaches. Due to the higher urbanization, along the coastline was observed several structures for shore protection.
\end{abstract}

Keywords: coastline tipology, coastal management, Olinda 


\section{Introdução}

A orla costeira é uma estreita faixa de contato do continente com o mar, na qual a ação dos processos costeiros se faz sentir de forma mais acentuada e potencialmente mais crítica, à medida que efeitos erosivos ou deposicionais podem alterar sensivelmente a configuração da linha de costa (Muehe, 2001). Esta faixa é formada por sedimentos inconsolidados, como as praias, ou por rochas, como as falésias ou costões rochosos. Seu equilíbrio dinâmico depende diretamente do balanço da constante interação entre fenômenos terrestres e marinhos.

O crescimento populacional e, muitas vezes, a conseqüente ocupação desordenada desta faixa, aumentam a pressão sobre os recursos costeiros, levando à degradação destes e de outros ecossistemas litorâneos, como os recifes, estuários, restingas, campos de dunas, entre outros, que têm a função de proteger o litoral. Considerando-se que dois terços das grandes cidades no mundo são litorâneos, podese concluir que a ausência de um programa de gerenciamento ambiental pode desencadear uma degradação destes ecossistemas.

O Brasil apresenta alta densidade demográfica na zona costeira (média de 87 hab. $\mathrm{Km}^{2}$ ), e no estado de Pernambuco a densidade populacional costeira é de $804,3 \mathrm{hab} . \mathrm{Km}^{2}$, considerada a maior do Brasil ( Costa \& Souza, 2002). Sobretudo nas últimas décadas, as zonas costeiras têm sido bastante afetadas pelo rápido crescimento urbano em seu entorno. Este processo de ocupação, muitas vezes desordenado, vem introduzindo graves problemas de usos e subsequentes conflitos, como a erosão costeira acelerada, por exemplo.

Segundo Pereira et al. (2003), 70\% da zona costeira do
Estado de Pernambuco, apresenta atualmente, algum problema de erosão marinha, devido, principalmente ao processo de ocupação intenso e desordenado destas áreas. A cidade de Olinda - $P E$ não constitui exceção a esta regra. Inúmeras são as ações impactantes, atreladas a soluções sem fundamentação científica, ineficazes e com reparos desastrosos, como a presença indevida de enrocamento, por exemplo, que vêm sendo efetuadas ao longo de sua zona costeira (Pereira et al., 1996, Pereira et al., 2000).

Visando o ordenamento de uso e ocupação da zona costeira brasileira, o Ministério do Meio Ambiente criou o Projeto Orla (MMA, 2001). De acordo com o referido projeto, o primeiro passo para este ordenamento é a realização de um diagnóstico, o qual inclui a descrição paisagística e o levantamento socioeconômico da orla costeira.

O objetivo deste trabalho é a caracterização das diversas tipologias paisagísticas da orla do município de Olinda-PE, analisand o o seu processo de urbanização, a forma e o grau de exposição da orla às ondas, usando a metodologia do Projeto Orla (MMA, 2001). Para melhor caracterização quanto ao grau de exposição às ondas, foi utilizada ainda a metodologia proposta por Muehe (2001). Estudos dessa natureza podem trazer subsídios para melhor direcionamento das ações de intervenção visando a contenção da erosão marinha, bem como auxiliar na minimização dos impactos negativos que porventura aconteçam, como por exemplo, a própria intensificação de ações antropogênicas.

\section{2. Área de estudo}

A cidade de Olinda situa-se na Região Metropolitana do Recife e limita-se ao norte com o município de Paulista, a leste com o Oceano Atlântico e a oeste e a sul com a cidade do Recife (Fig. 1).

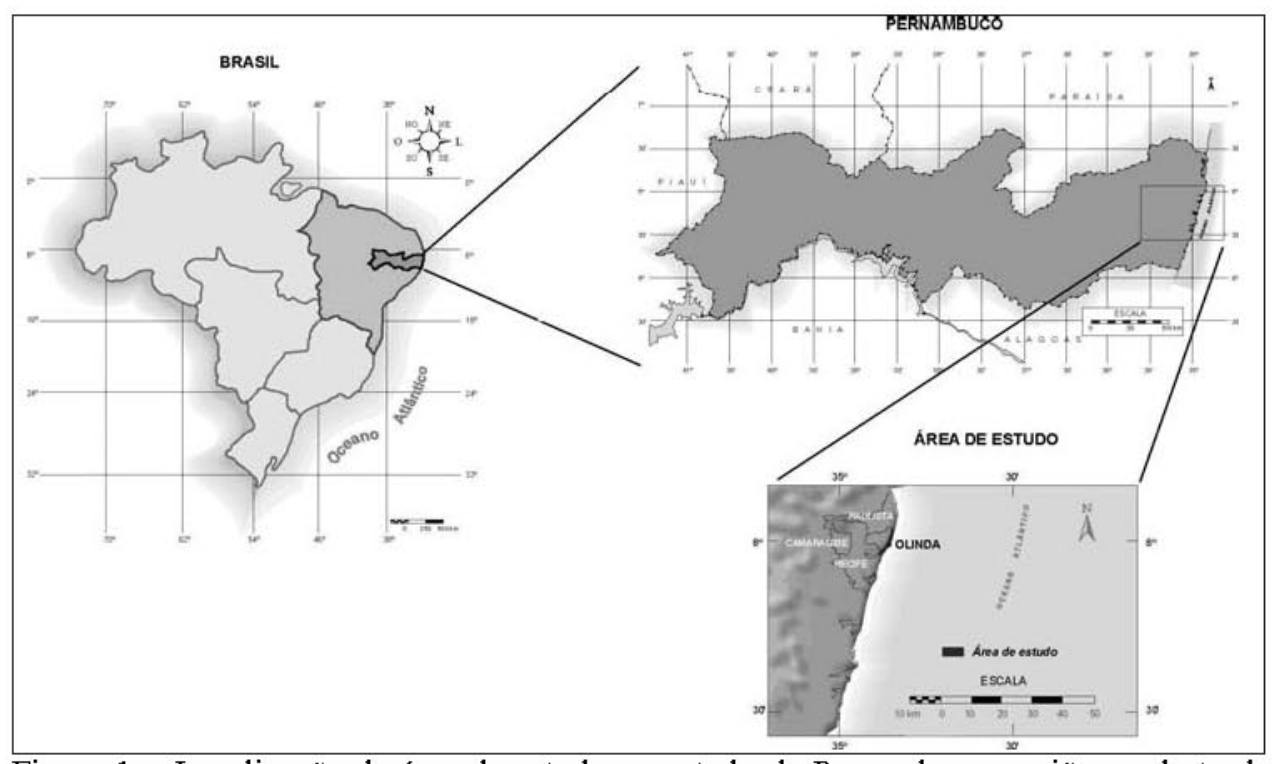

Figura 1 - Localização da área de estudo no estado de Pernambuco, região nordeste do Brasil. 
O clima da região é caracterizado por duas estações bem definidas: uma seca, entre os meses de setembro e fevereiro, e uma chuvosa, de março a agosto. Os ventos na área também mostram sazonalidade: os ventos mais fortes atuam na estação seca (ventos de SE), enquanto na estação chuv osa predominam os ventos moderados de NE (Pereira et al., 2003).

A orla costeira da cidade de Olinda tem uma extensão total de $9 \mathrm{~km}$, sendo constituída, de sul para norte, pelas praias Del Chifre, dos Milagres, do Carmo, de São Francisco, do Farol, Bairro Novo, Casa Caiada e Rio Doce (Fig. 1). - estágio atual da orla é o resultado da evolução das praias, forçadas pelas várias obras de contenção costeira que foram construídas ao longo do litoral, desde os anos 70 do século $\mathrm{XX}$. Atualmente, as seguintes obras de contenção são encontradas na orla da cidade de Olinda: dois quebra-mares na praia dos Milagres, trinta e oito espigões entre as praias do Carmo, Farol e Bairro Novo e sete quebra-mares e dois espigões entre as praias de Casa Caiada e Rio Doce (Pereira et al, 2003).

Olinda foi declarada Patrimônio Cultural da Humanidade pela UNESCO em 1882, devido ao seu grande valor histórico e cultural. Porém, várias intervenções introduzidas em sua orla fizeram com que suas praias tenham praticamente desaparecido em alguns trechos.

\section{Metodologia}

De acordo com o Projeto Orla (MMA, 2001), a definição do tipo de uma orla leva em conta o grau de exposição de uma praia às ondas (orla abrigada, orla exposta e orla semiabrigada) e o processo de urbanização (orla não urbanizada, orla em processo de urbanização e orla com urbanização consolidada). Com relação ao grau de exposição de uma praia, o Projeto Orla leva em consideração apenas os parâmetros paisagísticos. Porém, Muehe (2001) afirma que a inferência mais simples do grau de exposição de uma orla, quando não se conhece o clima de ondas, é a utilização da relação entre a inclinação da face praial e o diâmetro médio dos sedimentos.

Os trabalhos de campo foram realizados no mês de Outubro de 2002, e envolveram observações visuais dos parâmetros paisagísticos da orla (MMA, 2001), coleta de sedimentos superficiais e medida da inclinação da face de praia, além de registro fotográfico. Para uma melhor compreensão, foram realizados caminhamentos ao longo da área em períodos de maré baixa e alta, sempre nas marés de sizígia.

Os pontos de coleta de sedimentos e medida da inclinação da face praial (Fig. 2), foram definidos com o auxílio de um GPS Garmin, com um erro de 1 a 10 metros. Foram utilizadas como critério de definição destes pontos, as observações visuais do parâmetro da orla, ou seja, locais em que se pode definir claramente o tipo de orla através dos

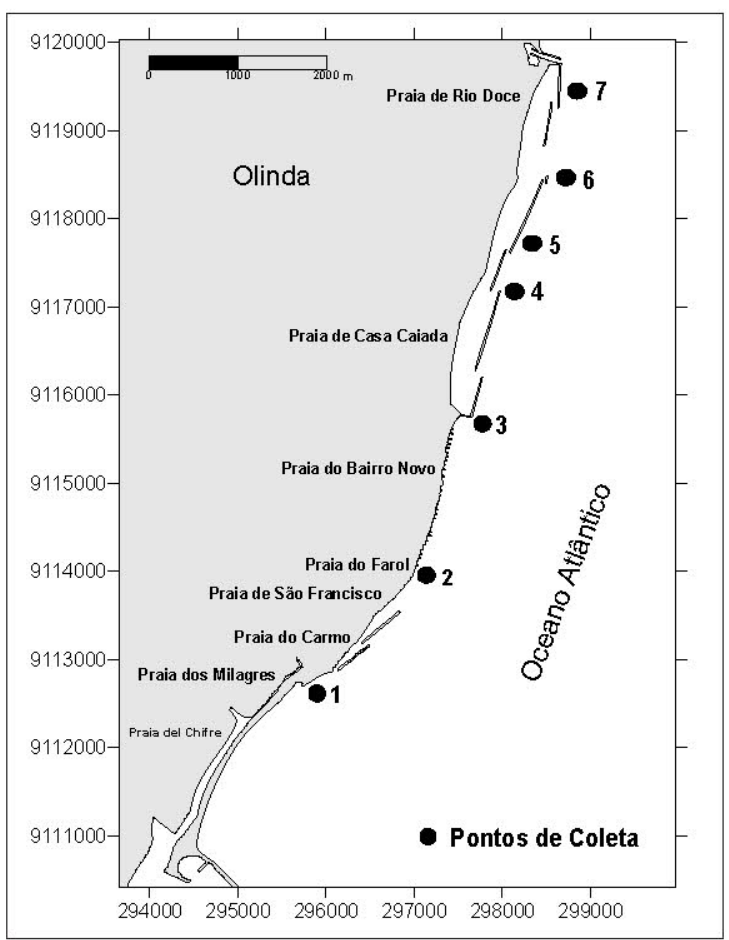

Figura 2 - Localização dos pontos analisados

parâmetros paisagísticos. O registro fotográfico foi feito ao longo de toda a orla estudada. Em laboratório, os pontos de observação foram plotados em um mapa base, tomando-se como referência às cartas da SUDENE, na escala de 1:25.000. Com base nos dados visuais levantados e com ajuda do registro fotográfico foi elaborada a classificação da tipologia da orla, segundo a metodologia do Projeto Orla (MMA, 2001).

As amostras de sedimentos superficiais ( 7 ao todo) foram analisadas no Laboratório de Oceanografia Geológica da Universidade Federal de Pernambuco, segundo a metodologia de Suguio (1973), envolvendo granulometria por peneiramento a úmido e a seco. Na primeira etapa foram utilizadas as peneiras com aberturas de 2 e $0,062 \mathrm{~mm}$. O material maior que $2 \mathrm{~mm}$ e o que ficou retido na peneira de $0,062 \mathrm{~mm}$, correspondente à fração cascalho e areia, respectivamente, foi colocado na estufa para secar. Posteriormente, o material que ficou retido na peneira de $0,062 \mathrm{~mm}$ foi submetido ao processo de peneiramento seco, onde foi utilizada uma seqüência de peneiras com abertura de $1 / 2 \mathrm{f}$. O resultado da análise granulométrica foi analisado pelo Software SYSGRAM. Por último, foi feita a relação entre diâm etro médio $x$ inclinação da face de praia, para comparação com a metodologia proposta por Muehe (2001).

\section{Resultados e Discussão}

De acordo com as observações visuais em relação ao grau de exposição da orla e o seu processo de urbanização 
foi possível classificar a tipologia da orla da cidade de Olinda em quatro classes: orla exposta não-urbanizada, orla exposta com urbanização consolidada, orla semi-abrigada com urbanização consolidada e orla abrigada com urbanização consolidada (Fig. 3).

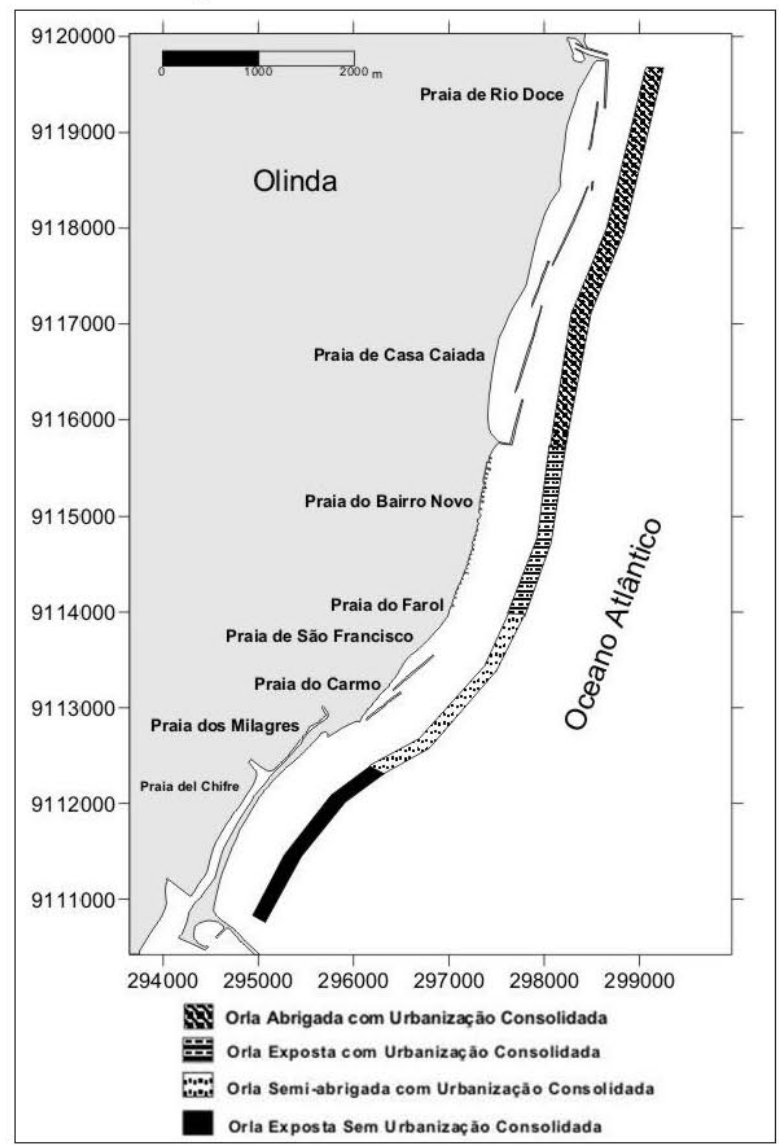

Figura 3 - Classificação da tipologia da orla

A orla exposta não-urbanizada é encontrada apenas no extremo sul, correspondendo à área do Istmo de Olinda, na praia dos Milagres. Representa $20 \%$ do litoral estudado. Mesmo estando situada entre as cidades de Recife e Olinda, seu processo de urbanização não se desenvolveu por ser área sob jurisdição federal da Marinha do Brasil.

No trecho compreendido entre a praia do Carmo e a praia de São Francisco (Fig. 3), a orla é classificada como semi-abrigada com urbanização consolidada, perfazendo $14 \%$ da área estudada. Neste trecho, várias intervenções foram feitas para conter a erosão marinha desencadeada desde a construção do Porto do Recife. Os vários quebra-mares construídos impedem a ação direta das ondas na praia, contribuindo assim para sua caracterização como orla semiabrigada (Figs - 4 e 5).

Rumo ao norte, no trecho compreendido entre a praia do Farol e do Bairro Novo, a ausência de obstáculos naturais e/ou artificiais à ação das ondas, dão ao mesmo características de orla exposta, ocupando $20 \%$ do litoral

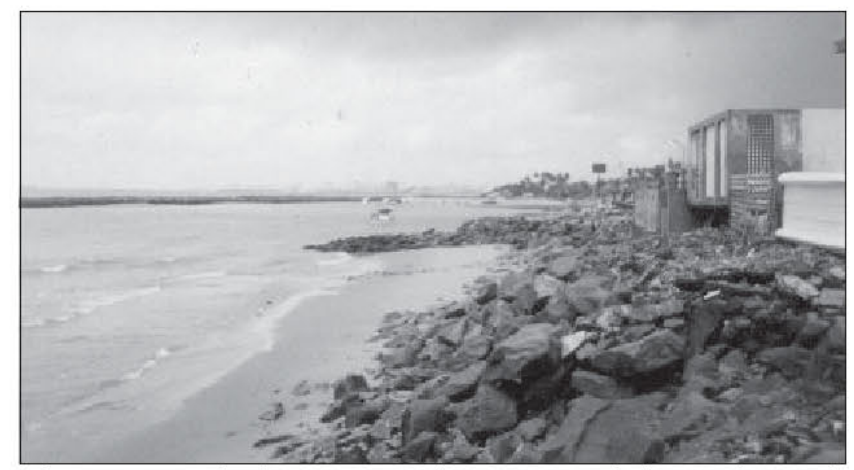

Figura 4 - Praia de São Francisco na maré baixa: orla semiabrigada com urbanização consolidada. Fotografia em período de maré baixa, visão para sul

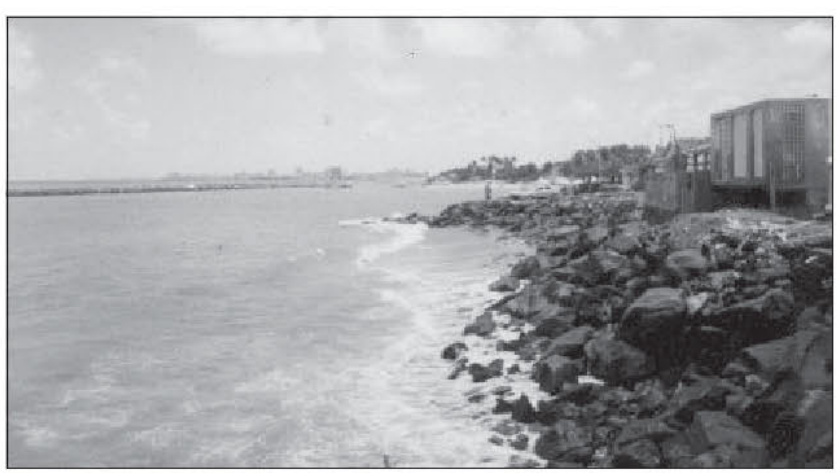

Figura 5-Mesmo trecho da praia de São Francisco, na maré alta, visão para sul.

estudado (Fig. 03). A orla encontra-se completamente urbanizada, com várias estruturas de proteção costeira, sendo um trecho sem praia recreativa em muitos locais (Fig. 6), ponto negativo para o turismo do Município, onde um dos atrativos é a balneabilidade de suas praias. No final deste trecho são encontrados vários diques, o que confere ao litoral, a partir deste ponto em direção ao extremo norte, uma situação abrigada com sérios problemas de circulação de água, principalmente na baixa mar.

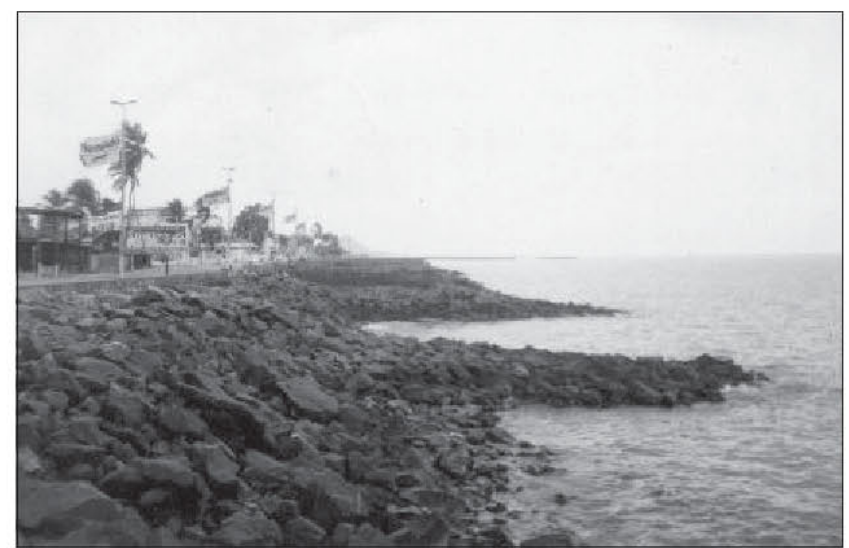

Figura 6-Praia do Bairro Novo: orla exposta com urbanização consolidada. Visão para norte. 
O trecho classificado como orla abrigada com urbanização consolidada ocupa $46 \%$ do litoral de Olinda, compreendendo as praias de Casa Caiada e Rio Doce, no extremo norte da área (Fig. 3). Éum trecho do litoral protegido da incidência direta das ondas (Figs. 7 e 8 ), e com circulação de água restrita, pela presença de sete quebra-mares e dois espigões. Estas estruturas, além de não terem resolvido o processo erosivo, ainda causaram sérios prejuízos com relação à erosão acelerada no litoral (Pereira, 2001). Tais estruturas são um exemplo dos vários impactos na área em questão, que reflete gestões políticas pautadas no imediatismo e sem fundamentação científica.

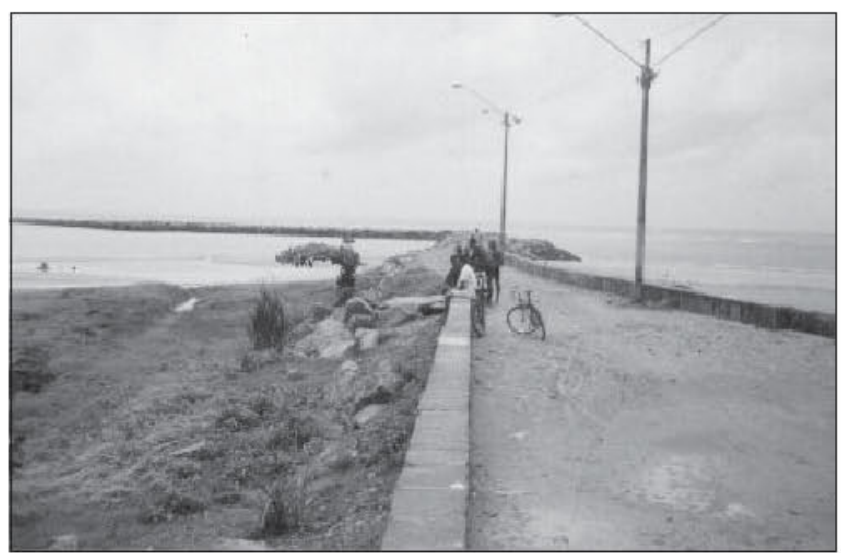

Figura 7-Praia de Casa Caiada: ponto que define a transição de orla exposta para orla abrigada com urbanização consolidada. Visão perpendicular à costa

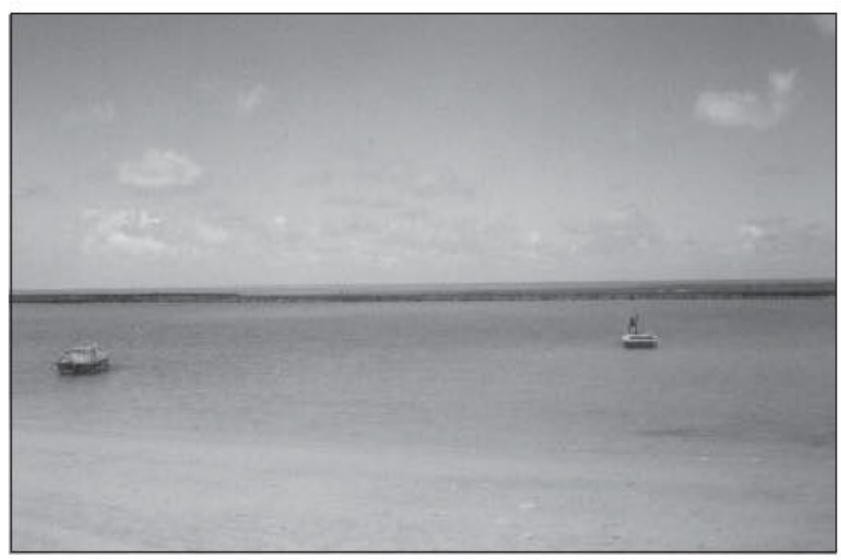

Figura 8-Praia do Rio Doce: orla abrigada com urbanização consolidada. Visão perpendicular à costa.

Visando obter mais subsídios para a classificação da orla quanto ao grau de exposição às ondas, foi testada a metodologia proposta por Muehe (2001). Os diâmetros médios dos grãos para as amostras analisadas, bem como as inclinações da face praial, encontram-se na Tabela 1 . Na Figura 09 pode-se observar a relação entre a declividade da face praial e a característica granulométrica dos sedimentos em função da exposição às ondas, em modelo proposto por Muehe (2001).

Tabela 1 -Diâmetro médio e inclinação da face praial, para cada amostra.

\begin{tabular}{|l|l|l|l|}
\hline Amostra & Diâmetro médio $(\phi)$ & Classificação & Inclinação $\left(^{\circ}\right)$ \\
\hline 1 & 2,138 & Areia fina & 6 \\
\hline 2 & 2,224 & Areia fina & 4 \\
\hline 3 & 1,328 & Areia média & 9 \\
\hline 4 & 1,883 & Areia média & 6 \\
\hline 5 & 1,093 & Areia média & 5 \\
\hline 6 & 2,005 & Areia fina & 4 \\
\hline 7 & 2,202 & Areia fina & 5 \\
\hline
\end{tabular}

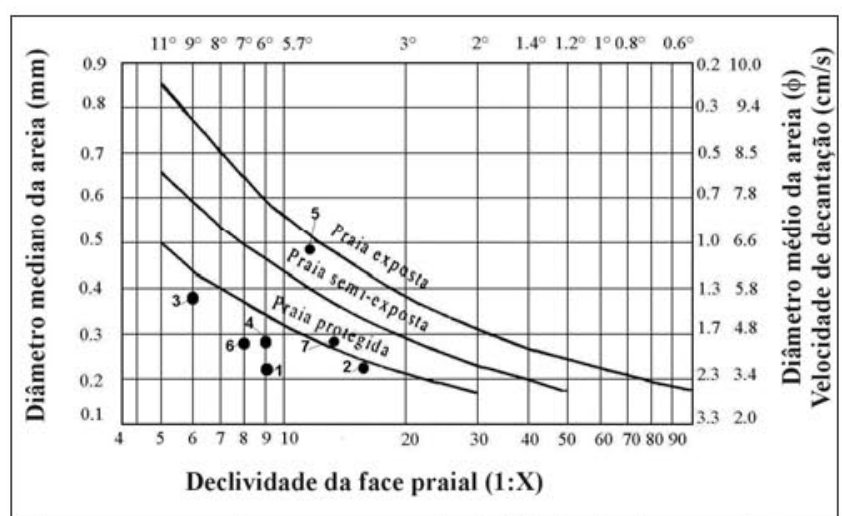

Figura 9 - Correlação entre a declividade da face praial e as características granulométricas dos sedimentos, segundo Muehe (2001).

A Tabela 02 apresenta a comparação entre a classificação visual (MMA, 2001) e a classificação de Muehe (2002).

Tabela 02-Classificação visual x Classifícação Muehe (2001).

\begin{tabular}{|l|l|l|}
\hline Amostra & Visual (MMA, 2001) & Muche (2001) \\
\hline 1 & Semi-abrigada & Protegida \\
\hline 2 & Exposta & Protegida \\
\hline 3 & Esposta & Protegida \\
\hline 4 & Abrigada & Protegida \\
\hline 5 & Abrigada & Semi-exposta \\
\hline 6 & Abrigada & Protegida \\
\hline 7 & Abrigrada & Protegida \\
\hline
\end{tabular}

Como pode-se observar na Fig. 9 e Tabela 2, os dados encontrados com a análise das observações visuais não apresentam concordância com o modelo de classificação proposto por Muehe (2001), em alguns pontos. No entanto, o mesmo autor ressalta que as classificações de praia exposta, semi-exposta e protegida utilizando a relação inclinação da face praial e a característica granulométrica dos sedimentos, é a inferência mais simples para se saber o grau de exposiçãoda orla. 
Outro fator a ser considerado, é o alto grau de degradação e descaracterização do local, fato que confere a toda a faixa costeira do município de Olinda um complexo e peculiar ambiente em virtude da diversidade das ações que descaracterizaram a área. Analisando sob esta ótica, podese supor que a metodologia não se enquadra, visto que as características físicas (granulometria dos sedimentos e grau de inclinação da face praial) do local estejam intensamente antropizadas, que não correspondem às características das tipologias classificadas por parâmetros paisagísticos (Tabela $02)$.

É interessante observar que, baseada na relação granulometria versus declividade, toda parte sul da área é classificada como orla protegida. Porém, na praia do Carmo a caracterização é tipicamente de orla exposta. As várias intervenções antrópicas sofridas por este litoral, podem ter contribuído para que os sedimentos encontrados hoje no ambiente não sejam representativos das condições naturais. Talvez, a mesma explicação seja válida para a praia de Casa Caiada (abrigada), classificada como semi-exposta. Assim, vários impactos ambientais neste litoral podem estar contribuindo para a descaracterização da cobertura sedimentar. A própria história do município de Olinda já é marcada por tentativas sem sucesso de engordamento de praias com sedimentos retirados de outro local.

Diante do exposto, pode-se vislumbrar uma relação paradoxal quanto ao potencial de balneabilidade e a atual forma de manejo da área. O município de Olinda-PE pelo seu vultoso passado histórico e sua representatividade econômica no NE do Brasil não poderia encontrar-se na situação atual. Aaplicação de metodologias de classificações paisagísticas constitui uma importante ferramenta para futuros trabalhos no sentido de reverter ou ao menos minimizar a situação do local em pauta, vítima de um problema que atinge a maioria das metrópoles litorâneas do Brasil e do Mundo.

\section{Conclusão}

Em relação ao grau de exposição da praia, a orla da cidade de Olinda foi classificada em $40 \%$ como exposta, $46 \%$ como abrigada, enquanto apenas $14 \%$ como semi-abrigada. $\mathrm{Na}$ parte sul predomina a orla exposta, enquanto que praticamente toda a parte norte do litoral, é composta de orla protegida.

Levando em consideração o grau de urbanização, $80 \%$ da orla é classificada como com urbanização consolidada, e apenas $20 \%$ sem urbanização. Este trecho corresponde ao Istmo de Olinda, uma estreita faixa de areia no extremo sul da cidade, que se encontra sob jurisdição da Marinha do Brasil.

Foi também constatado que, provavelmente, as constantes intervenções antrópicas mudaram as características da cobertura sedimentar das praias.
Em toda a área foi constatada a presença de obras de proteção, em decorrência da grande densidade demográfica e do alto nível de urbanização na orla da cidade de Olinda. A população local usa a orla não só para morar, mas também para recreação, lazer e atividades de pesca. Na maior parte do litoral a circulação de água é restrita, acarretando freqüentemente problemas de poluição local.

\section{Referências Bibliográficas}

Costa, M.; Sousa, S. T. (2002) A zona costeira pernambucana e o caso especial da praia da Boa Viagem: usos e conflitos. In: Yoshyia Nakagawara Ferreira. (Org.). Construção do saber Urbano Ambiental: a caminho da transdisciplinaridade. 1 ed. Londrina - PR: Humanidades, 2002, v. 1, p. 1-20

MMAMinistério do Meio Ambiente.(2001) Projeto de Gestão Integrada da Orla Marítima., 110p.

Muehe, D.(2001) Critérios morfodinâmicos para o estabelecimento de limites da orla costeira para fins de gerenciamento. Revista Brasileira de Geomorfologia 2(1): 35-43.

Pereira, L.C.C.(2001) Procesos litorales a lo largo de las playas de Casa Caiada y Rio Doce, Olinda-PE (Brasil): Implicaciones para gestión costera. Tese de Doutorado, Univesidade Politécnica da Calunha. $166 \mathrm{p}$.

Pereira, L.C.C, Coutinho, P.N., Macedo, S.J., Costa, R.A.A.M.(1996) Efeitos de estruturas de proteção costeira nas praias de Casa Caiada e Rio Doce PE, Brasil. Trabalhos Oceanográficos da Universidade Federal de Pernambuco, 24:19-37.

Pereira, L.C.C., Jimenez, J.A., Medeiros, C.(2000) Environmental degradation of the littoral of Casa Caiada and Rio Doce, Olinda-PE (Brazil). Simpósio Brasileiro sobre Praias Arenosas: Morfodinâmica, Ecologia, Usos, Riscos e Gestão. 329-331.

Pereira, L.C.C., Jimenez, J.A., Medeiros, C. Costa, R. M. (2003) The influence of the environmental status of Casa Caiada and Rio Doce beaches (NE-Brazil) on beaches users. Ocean \& Coastal Management, 46:1011-1030.

Suguio, K.(1973) Introdução a Sedimentologia. Edgard Blucher, $317 \mathrm{p}$. 